\title{
TRACE ELEMENTS IN ANTARCTIC AIR AND SNOWFALL
}

\author{
by
}

\author{
A.L. Dick and D.A. Peel
}

(British Antarctic Survey, Natural Environment Research Council, High Cross, Madingley Road, Cambridge CB3 OET, England)

\begin{abstract}
Measurements of trace elements in snow and ice are frequently used to describe past atmospheric composition although there is no firm basis for assuming a direct connection. Trace-element concentrations have been measured on samples of aerosol and freshly fallen snow collected simultaneously from two sites in the Antarctic Peninsula during summer. Following improvements in contamination control, the reported concentrations and crustal enrichment factors of $\mathrm{Cd}, \mathrm{Cu}, \mathrm{Pb}$ and $\mathrm{Zn}$ in the aerosol are lower than any values previously reported from Antarctica. Even tighter controls will be required in the future.

For a crustal element (A1) and for the marine cations $(\mathrm{Na}, \mathrm{Ca}$ and $\mathrm{K})$ a consistent ratio $(0.48 \pm 0.31)$ for the concentration in air $\left(\mathrm{pg} \mathrm{m}^{-3}\right) /$ concentration in snow $\left(\mathrm{pg} \mathrm{g}^{-1}\right)$ is obtained for simultaneously collected samples. This supports a simple model of aerosol scavenging proposed by Junge which considers aerosol removal over polar ice sheets to be dominated by in-cloud processes. Averaged data for $\mathrm{Cd}, \mathrm{Cu}, \mathrm{Pb}$ and $\mathrm{Zn}$ from samples collected at different times appear to behave similarly. These findings suggest that there is no preferential scavenging by snowfall of either crustal or heavy metal components in contemporary aerosol. If proved more general in Antarctica this may help to simplify the interpretation of time series data from ice cores.
\end{abstract}

\section{INTRODUCTION}

Ice cores collected from remote polar regions are being widely studied in order to establish a record of trends in global air pollution. These studies assume that observed changes in the trace chemical composition of snow may be related directly to changes in composition of the atmospheric aerosol.

Junge (1977) has argued that for remote, clean-air situations the normally complex processes of aerosol removal are dominated by the uptake of a large proportion of the aerosol population as condensation nuclei. This process should lead to a linear relationship between the concentration of a given element in air and the corresponding concentration in snowfall. Two experimental studies on polar ice sheets (Davidson and others 1981, Peel and Wolff 1982) have attempted to test these conclusions directly by sampling aerosol and snowfall simultaneously. Other comparisons have been made between aerosol and snowfall collected at different times (Boutron and Lorius 1979). Although crude and mainly derived from averaged samples and conditions, the results tend to support Junge's predictions.

Nevertheless there is some evidence from other remote sites (Rahn and McCaffrey 1979, Ng and Patterson 1981) that fractionation during the aerosol scavenging process can occur between aerosols derived from crustal and anthropogenic sources. Furthermore dry deposition could be an important factor for larger particles (Davidson and others 1981). Both processes could seriously perturb the relationship between profiles of compositional changes along an ice core and actual changes in the trace content of the atmosphere. In addition recent improvements in the analysis of snow and ice have cast doubt on much of the earlier data on the concentrations of trace elements in Antarctic snow and air on which the earlier comparisons were based (Boutron and Patterson 1983, Boutron in press). Clearly there is an urgent need for more precisely controlled data from simultaneously sampled air and snowfall.

In the present study aerosol and snowfall collections were made at two remote locations in the Antarctic Peninsula during a period of three months in summer 1982-83. Particular care has been taken to improve the quality of the aerosol collections by reducing the size and variability of filter blank corrections. Such corrections were particularly severe for the heavy metals in earlier work. This study now includes analysis of Al as a crustal reference element along with the analysis of $\mathrm{Na}, \mathrm{K}$ and $\mathrm{Ca}$ derived mainly from an oceanic source. Whilst most of the data relate to the aerosol, some elements have been analyzed in a small number of snowfall samples collected during the same period, allowing a further test of Junge's predictions in a polar location.

\section{SAMPLE COLLECTION}

Sampling was carried out at two sites (Fig.1) which experienced contrasting weather patterns in order to test the representativeness of derived relationships between aerosol and snowfall composition. The sites lay at different distances from exposed rock and the sea and hence were likely to experience differences in the size population of aerosols derived from these local sources. No other field activity was being undertaken within $60 \mathrm{~km}$ of either site whilst sampling was under way.

Aerosol sampling was carried out during December 1982 at a snow dome on the Beethoven Peninsula ( $71^{\circ} 50$ 'S, $74^{\circ} 30^{\prime} \mathrm{W}$, altitude $825 \mathrm{~m}$ a.s.1.). This site was subject to a maritime climate; open sea-water approaches within $26 \mathrm{~km}$ during the summer and the nearest exposed rock lay $31 \mathrm{~km}$ to the north-east. Further sampling was conducted at a site $16 \mathrm{~km}$ south of Crescent Scarp $\left(69^{\circ} 42\right.$ 'S, $66^{\circ} 25^{\prime} \mathrm{W}$, altitude $1500 \mathrm{~m}$ a.s.1.) during January and February 1983. More remote from open sea-water $(90 \mathrm{~km}$ minimum $)$ this high-altitude plateau site experienced more settled weather

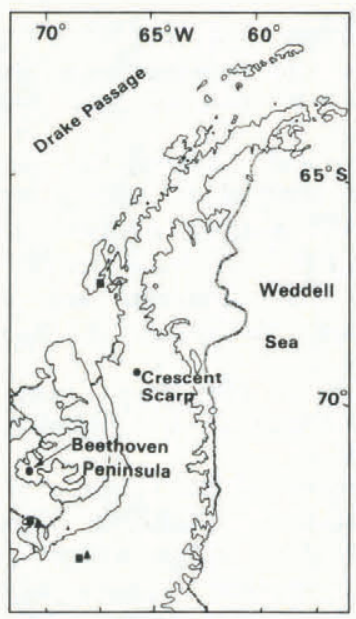

Fig.1. Sample collection sites in the Antarctic Peninsula. Circles indicate simultaneous aerosol/snowfall sampling (this work), squares indicate simultaneous aerosol/snowfall sampling (Peel and Wolff 1982), and triangles indicate snow sampling only (Wolff and Peel 1985). 
conditions during sampling. The nearest exposed rock was at Crescent Scarp.

Aerosol sampling was carried out for a total period of $900 \mathrm{~h}$, in 33 runs lasting between 15 and $52 \mathrm{~h}$. Details of individual runs used so far in analysis are given in Table I. Supporting weather observations were made during waking hours at intervals of $3 \mathrm{~h}$ throughout the period of occupation. Freshly fallen snow was sampled at intervals as it occurred.

\subsection{Aerosol sampling}

Two low-volume sampling systems were deployed simultaneously to collect the aerosol onto membrane filters

\section{TABLE I. SUMMARY OF AEROSOL SAMPLE COLLECTIONS}

BEETHOVEN PENINSULA:

$\begin{array}{cccc}\begin{array}{c}\text { Run } \\ \text { no. }\end{array} & \text { Start } & \begin{array}{c}\text { Duration } \\ (\mathrm{h})\end{array} & \begin{array}{c}\text { Volume of air } \\ \left(\mathrm{m}^{3}\right) \\ \mathrm{STP} / \mathrm{f} \text { ilter }\end{array}\end{array}$

\begin{tabular}{|c|c|c|c|c|c|}
\hline 3 & 9 & Dec & 25 & 16 & $\begin{array}{l}\text { Snowfall }<1 \mathrm{~mm} \\
\text { Cloud base } \\
0-300 \mathrm{~m} \text { stratus }\end{array}$ \\
\hline 4 & 10 & Dec & 23 & 21 & $\begin{array}{l}\text { Snowfall } 3 \mathrm{~cm} \\
\text { continuous } \\
\text { Cloud base } \\
0-100 \mathrm{~m} \text { stratus }\end{array}$ \\
\hline 5 & 11 & Dec & 22 & 23 & $\begin{array}{l}\text { Snowfall } 2 \mathrm{~cm} \\
\text { continuous } \\
\text { Cloud base } \\
0-100 \mathrm{~m} \text { stratus }\end{array}$ \\
\hline 6 & 13 & Dec & 43 & 29 & Snowfall nil \\
\hline 12 & 22 & Dec & 39 & 34 & Snowfall nil \\
\hline
\end{tabular}

\section{PLATEAU NEAR CRESCENT SCARP:}

\begin{tabular}{|c|c|c|c|}
\hline $\begin{array}{r}\text { Run } \\
\text { no. }\end{array}$ & Start & $\begin{array}{l}\text { Duration } \\
\text { (h) }\end{array}$ & $\begin{array}{l}\text { Volume of air } \\
\left(\mathrm{m}^{3}\right) \\
\text { STP/filter }\end{array}$ \\
\hline
\end{tabular}

$14 \quad 27$ Jan $\quad 48 \quad 38 \quad$ Snowfall $7 \mathrm{~cm}$ continuous

Cloud base

0-70 m stratus

$\begin{array}{lllll}15 & 29 \mathrm{Jan} & 24 & 17 & \begin{array}{l}\text { Snowfall } 10 \mathrm{~cm} \\ \text { continuous } \\ \text { Cloud base } \\ \end{array} \\ & & 30-70 \mathrm{~m} \text { stratus }\end{array}$

$16 \quad 30$ Jan $24 \quad 14 \quad$ Snowfall $4 \mathrm{~cm}$

continuous

Cloud base

30-300 m stratus

22

24

30

Snowfall nil

Snowfall $0.5 \mathrm{~cm}$

Cloud base

$1000-0 \mathrm{~m}$ stratus

$23 \quad 11 \mathrm{Feb}$

29

16

Snowfall $15 \mathrm{~cm}$

Cloud base

0-30 m stratus

$24 \quad 13 \mathrm{Feb}$

19

11

Snowfall $12 \mathrm{~cm}$

Cloud base

$0-30 \mathrm{~m}$ stratus

$26 \quad 16 \mathrm{Feb}$

24

14

Snowfall nil
(37 mm diameter). A Sartorius collector (42 1 min ${ }^{-1}$ displacement) powered by a $500 \mathrm{~W}$ generator drew air through two sampling probes in parallel, at a flow rate of $11 \pm 11 \mathrm{~min}^{-1}$ for a $0.45 \mu \mathrm{m}$ pore-size filter (face velocity, $21 \pm 2 \mathrm{~cm} \mathrm{~s}^{-1}$ ). In the second system a Gast rotary-vane air pump (242 $1 \mathrm{~min}^{-1}$ displacement) powered by a $1 \mathrm{~kW}$ generator was connected to three sampling probes giving a flow rate of $16 \pm 21 \mathrm{~min}^{-1}$ per filter. In both cases the air was exhausted via gum rubber tubing through a dry gas meter and a flow-rate meter. Both the temperature of the exhausted air and the atmospheric pressure were monitored. The generators were modified for use with propane to avoid leaded fuel.

The filters were taken into the field in disposable styrene filter holders. These were mounted face downwards in acid-washed, heavy-duty polypropylene jars to prevent blockage by snowfall or drift. The probes were suspended about $1.5 \mathrm{~m}$ above the snow surface from nylon lines which were supported by acetal poles. The pumps and metering systems were sited $12 \mathrm{~m}$ downwind inside a snow shelter to reduce contact with the ambient air. The generators and camp site were in turn $200 \mathrm{~m}$ further downwind and the generators were connected to a wind-speed and direction switching unit which turned the system off if the wind slackened or moved into an unfavourable sector. The limits were usually $0.7 \mathrm{~m} \mathrm{~s}^{-1}$ or $\pm 90^{\circ}$ vector from the direct line between the camp site and the sampling area. Throughout, the sampling and pumping areas were approached only by personnel wearing full clean-area garments. There were no snowmobiles at either sampling site. Filter changeover could be achieved rapidly with minimal risk of contamination. After exposure the filter holders were double-packed in pre-cleaned polyethylene bags and returned to the laboratory under deep freeze. Blank filters were treated in exactly the same way and left exposed for the duration of a normal run alongside authentic samples. In these cases air was pumped through the filter for a few minutes only.

\subsection{Snow sampling}

Areas were set aside cross-wind from the air sampling probes for the collection of both fresh and aged surface snow. Samples were scooped upwind of the operator directly into pre-cleaned polyethlene (LPE) 21 bottles. These were sealed into polyethlene bags and returned under deep freeze to the laboratory. During prolonged snowfall, fresh snow was collected at regular intervals from the upper 2 to $3 \mathrm{~cm}$ in an attempt to monitor changes in composition during the course of the snowfall.

\section{LABORATORY PROCEDURES}

With the exception of the final stage of analysis on an atomic absorption spectrometer (AAS), all laboratory procedures took place inside a class- 100 laminar flow bench within a clean-air laboratory used only for ultra-trace element analysis. The graphite rod of the AAS was positioned across a stream of piped clean air and no significant blank was detected for this stage of the analysis.

All equipment used in the analysis and the polyethylene bottles used for snow-sample collection were cleaned by progressive acid washes following the procedure given by Wolff and Peel (1985). The sample bottles were finally tested by filling them with "purest water" $\left(0.05 \mathrm{pg} \mathrm{g}^{-1} \mathrm{Cd}\right.$, $0.4 \mathrm{pg} \mathrm{g}^{-1} \mathrm{Cu}, 1.5 \mathrm{pg} \mathrm{g}^{-1} \mathrm{~Pb}, 1 \mathrm{pg} \mathrm{g}^{-1} \mathrm{Zn},<0.05 \mathrm{ng} \mathrm{g}^{-1}$ $\mathrm{Al},<0.07 \mathrm{ng} \mathrm{g}^{-1} \mathrm{Na},<0.05 \mathrm{ng}^{-1} \mathrm{Ca}$ and $\mathrm{K}$ ) acidified to pH 2.7 ("Aristar: $\mathrm{HNO}_{3}$ ). After a period of $2 \mathrm{~d}$ no increase in the concentration of $\mathrm{Zn}\left(1 \mathrm{pg} \mathrm{g}^{-1}\right)$ was detected. The filter holders were cleaned by successive soaks for $24 \mathrm{~h}$ in $10 \% \mathrm{HNO}_{3}$ ("Analar") followed by "purest water" acidified to pH 2.7 (twice). They were finally sonicated in "purest water" and rinsed in "purest water" before being sealed in polythene bags (double-wrapped) for shipment. The innermost, re-sealable polythene bags used to ship both the snow-sample bottles and the filter holders were soaked for $10 \mathrm{~min}$ in "purest water" acidified to $\mathrm{pH} 2.7$, sonicated in fresh "purest water" acidified to $\mathrm{pH} \mathrm{2.7,} \mathrm{and} \mathrm{finally} \mathrm{rinsed}$ in "purest water". The filter holders, bottles and bags were dried on plastic trays within the laminar-flow bench. 


\subsection{Filter selection and pre-cleaning}

Standard aerosol collections were made on $0.45 \mu \mathrm{m}$ pore size, tortuous pore, membrane filters. Their collection efficiency is essentially quantitative for particles larger than $0.02 \mu \mathrm{m}$ in diameter (Megaw and Wiffen 1963). In order to reduce the filter contribution to the blank the trace-element content of several filter types was determined. The optimum filters were then pre-cleaned before mounting them in their disposable filter holders for shipment.

The heavy-metal content of eight types of filter and three types of support pad were determined under similar conditions used for analyzing authentic samples. Each filter was placed in a PTFE beaker using PTFE tweezers. $5.3 \mathrm{ml}$ of "purest water" was pipetted into the vessel and acidified to $\mathrm{pH} 2.7$ with "Aristar" $\mathrm{HNO}_{3}$. After intermittent agitation for $30 \mathrm{~min}$, aliquots of the solution were transferred to 30 $\mathrm{ml}$ FEP bottles. The samples were analyzed immediately for $\mathrm{Cd}, \mathrm{Cu}, \mathrm{Pb}$ and $\mathrm{Zn}$ by direct-injection flameless AAS. Analyses of 12 filters and six support pads of each type were carried out and the mean trace contents of the filters with their standard deviations are presented in Table II.

Although the PTFE filters appeared to give the most favourable blanks this may simply be a reflection of their poor wetting properties. The use of a wetting agent such as ethanol has been suggested (Derrick and Moyers 1981) but this would increase the risk of contamination. Nucleopore polycarbonate filters eluted small concentrations of the heavy metals but pre-cleaning proved difficult dus to problems with handling the filters whilst wet. Finally it was decided to standardise on Sartorius SM111 06 filters $(0.45 \mu \mathrm{m}$ pore, cellulose acetate) which offered a good compromise, with low initial heavy-metal content combined with ease of handling whilst wet. Millipore AP 1003700 support pads were used as supplied since tests showed that contact between the filter and the support pad and the filter holder did not significantly raise the blank.

The filters were cleaned by soaking in three changes of "purest water" acidified to $\mathrm{pH} 2.7$ for periods of $1 \mathrm{~h}$, rinsing with "purest water" between soaks. Finally they were rinsed twice in "purest water" and dried overnight on a PTFE grid inside a polycarbonate dessicator. Full procedural blanks for the heavy metal contribution from the pre-cleaned filters are given in Table II. They are some four times smaller than the values for un-cleaned filters and ten times smaller than the blanks reported by Peel and Wolff (1982). The corresponding blanks for other elements studied here were: Al $(9.6 \pm 5.0 \mathrm{ng}$ per filter $), \mathrm{Ca}(9.6 \pm$
$1.9 \mathrm{ng}$ per filter), $\mathrm{Na}(10.1 \pm 7.0 \mathrm{ng}$ per filter $)$ and $\mathrm{K}$ $(12.1 \pm 9.8 \mathrm{ng}$ per filter).

\subsection{Filter analysis}

Filters were transferred to a PFTE beaker using PTFE tweezers and eluted with $7.42 \mathrm{ml}$ "purest water" acidified to pH 2.7 with "Aristar" $\mathrm{HNO}_{3}$ for $1 \mathrm{~h}$. There was a $10 \mathrm{~min}$ period of sonication at the beginning and end of the process. Then $4 \mathrm{ml}$ of the eluate was pipetted into a $30 \mathrm{ml}$ FEP bottle and immediately frozen. These samples were melted within $48 \mathrm{~h}$ and analyzed for $\mathrm{Al}, \mathrm{Cd}, \mathrm{Cu}, \mathrm{Pb}$ and $\mathrm{Zn}$ by flameless AAS using multiple injections. The residual eluate was pipetted into a second FEP bottle, weighed and diluted with $3 \mathrm{ml}$ "purest water" and then frozen. Within 72 $\mathrm{h}$ these samples were analyzed for $\mathrm{Ca}$ by flameless AAS and for $\mathrm{Na}$ and $\mathrm{K}$ by flame emission spectrometry. Calibration sequences using mixed standards were distributed within authentic analyses. Simulated samples analyzed before and after freezing showed no significant change in composition. The rather mild acid conditions used in the elution step paralleled conditions required in our procedures used for analyzing heavy metals in snow samples (Wolff and Peel 1985). At the same time they avoid dissolution of the filter matrix which may increase the blank contribution. There is however a risk that a significant proportion of the heavy metals and A1 may not be released.

A check on the efficiency of extraction and acid-releasable elements was made by carrying out a second identical elution step immediately following the first one. Six exposed filters and three blank filters were examined. More than $90 \%$ of available $\mathrm{Zn}$ and $\mathrm{Cu}$ was removed in the first elution of five filters; concentrations in the sixth filter lay close to detection limits (blank levels). The levels of $\mathrm{Pb}$ and $\mathrm{Cd}$ were undetectable above the blank in these samples. The marine ions were never detected in the second eluate above the amount carried over in the wet filter $(\sim 10 \%)$. Several investigations (Nguyen and others 1979, Nurnberg and others 1982, Rohbok 1982) on rural rainwater have shown that more than $90 \%$ of available $\mathrm{Cd}, \mathrm{Cu}, \mathrm{Pb}$ and $\mathrm{Zn}$ is dissolved at around $\mathrm{pH}$ 3. Consequently we believe that the analytical conditions release into solution a high proportion of the heavy metals involved in long-range transport. A small component will remain bound firmly as insoluble silicate complexes.

The efficiency of extraction of aluminium was investigated on filters exposed near Cambridge. Filters were exposed in pairs. One filter was taken through two elution

TABLE II. COMPOSITION OF DIFFERENT FILTER TYPES (concentrations in ng per filter)

\begin{tabular}{|c|c|c|c|c|c|c|c|c|c|c|c|}
\hline Type & Material & Pore $(\mu \mathrm{m})$ & & $\mathrm{Cd}$ & & $\mathrm{Cu}$ & & $\mathrm{Pb}$ & & $\mathrm{Zn}$ & \\
\hline Millipore AAWP* & $\begin{array}{l}\text { mixed cellulose } \\
\text { acetate/nitrate }\end{array}$ & 0.8 & 0.136 & \pm 0.018 & 5.06 & \pm 0.22 & $1.96 \pm$ & \pm 0.16 & 258 & \pm & 20 \\
\hline Millipore EHWP* & cellulose acetate & 0.5 & 0.139 & \pm 0.077 & 8.62 & \pm 0.69 & $2.94=$ & \pm 0.87 & 4.89 & \pm & 0.60 \\
\hline Millipore MHWP & $\begin{array}{l}\text { mixed cellulose } \\
\text { acetate/nitrate }\end{array}$ & 0.45 & 0.087 & \pm 0.042 & 88.8 & \pm 9.9 & $3.78=$ & \pm 1.27 & 389 & \pm & 32 \\
\hline Sartorius SM111 & cellulose acetate & 0.8 & 0.052 & \pm 0.014 & 3.33 & \pm 0.60 & $0.94 \pm$ & \pm 0.19 & 4.42 & \pm & 0.70 \\
\hline Sartorius SM111 & cellulose acetate & 0.45 & 0.051 & \pm 0.012 & 2.97 & \pm 0.24 & $0.71 \pm$ & \pm 0.17 & 3.38 & \pm & 0.52 \\
\hline Sartorius SM118 & PTFE & 0.45 & & $<0.05$ & & $<0.8$ & & $<0.8$ & 0.89 & \pm & 0.67 \\
\hline Nucleopore 110830 & polycarbonate & 0.4 & 0.075 & \pm 0.011 & 0.68 & \pm 0.11 & $1.44=$ & \pm 0.44 & 1.78 & \pm & 0.25 \\
\hline Nucleopore 110831 & polycarbonate & 8.0 & 0.048 & \pm 0.014 & 1.36 & \pm 0.14 & $0.79 \pm$ & \pm 0.19 & 0.68 & \pm & 0.16 \\
\hline $\begin{array}{l}\text { Sartorius SM111 } \\
\text { after pre-cleaning }\end{array}$ & cellulose acetate & 0.45 & 0.040 & \pm 0.012 & 0.655 & \pm 0.099 & 0.172 & \pm 0.20 & 0.423 & \pm & 0.087 \\
\hline
\end{tabular}

* $47 \mathrm{~mm}$ diameter. All other filters $37 \mathrm{~mm}$ diameter. 
stages following our normal procedures; the other was analyzed by neutron activation analysis (INAA), at the Atomic Energy Research Establishment, Harwell. More than $92 \%$ of A1 was analyzed in the first elution stage using $\mathrm{HNO}_{3}$ at $\mathrm{pH}$ 3. There was a good correspondence between the data obtained from INAA and from flameless AAS.

\subsection{Snow sample analysis}

Working in a laminar-flow work station at $-22^{\circ} \mathrm{C}$ subcores were taken from the snow samples using a PTFE tube (20 $\mathrm{mm}$ inside diameter). In general two sub-samples were taken from each container. The first sampled the top 1 to $2 \mathrm{~cm}$ of the sample only whilst the second penetrated the centre. In the one case (run 22) where elevated concentrations were detected in the upper sub-sample the results from the central sub-sample are quoted as upper limits. For one sample, three sub-cores were taken across the bottle from the outer surface towards the centre. Constant levels of $\mathrm{Na}, \mathrm{K}, \mathrm{Al}$ and $\mathrm{Ca}$ were measured, indicating that there was no significant contamination of the sample by the container walls. The sub-cores were transferred to ultra-clean PTFE beakers where they were melted in a microwave oven. Following acidification to $\mathrm{pH}$ 2.7 with "Aristar" $\mathrm{HNO}_{3}$ the samples were transferred to 30 $\mathrm{ml}$ FEP bottles for analysis. $\mathrm{Al}$ and $\mathrm{Ca}$ were analyzed by direct injection on a flameless AAS. $\mathrm{Na}$ and $\mathrm{K}$ were analyzed by flame emission spectrometry.

\section{RESULTS AND DISCUSSION}

Measured airborne concentrations $\left(\mathrm{C}_{\mathrm{air}}\right)$ of a range of trace elements at two sampling sites are given in Table III. Volumes of air in the range 11 to $38 \mathrm{~m}^{3}$ STP were sampled through each filter in runs of between 19 and $51 \mathrm{~h}$. Each value represents the mean from two filters exposed simultaneously. In each case a filter blank has been subtracted; calculated as the average of eight exposed filter blanks.

The total estimated analytical error $\left(\sigma_{\text {tot }}\right)$ includes a contribution from random analytical errors $\left(\sigma_{a n a l}\right)$ and from errors in the procedural blank $\left(\sigma_{\text {blank }}\right) \cdot \sigma_{\text {anal }}$ was estimated from the standard deviation of points on the AAS calibration plot about the best fit line. $\sigma_{\text {blank combines a }}$ random analytical error and real variations in the composition of the filter. This has been calculated directly from the variance of the eight filter blanks and probably slightly overestimates the uncertainty in the blank. The analytical errors cited in Table III were calculated as:

$\sigma_{\text {tot }}\left(\mathrm{pg} \mathrm{m} \mathrm{m}^{-3}\right)=v\left(\sigma_{\text {anal }}{ }^{2}+\sigma_{\text {blank }}{ }^{2}\right) /(\sqrt{2} \times$ volume of air sampled)

Where the concentration falls below $1.64 \sigma_{\text {tot }}$ ( $95 \%$ confidence level $)$ an upper limit is quoted as $<\left(\mathrm{C}_{\mathrm{air}}+\right.$ $\left.1.64 \sigma_{\text {tot }}\right)$.

Measured concentrations in snowfall which accompanied several air sampling runs are presented in Table IV. In general each value represents the average of duplicated samples. Analytical errors were calculated in a similar way to methods outlined for the air samples. In this case the procedural blanks were estimated from samples of "purest water" which were taken through all the wet chemical stages of an authentic analysis.

\subsection{Trace elements in the Antarctic aerosol}

Most of the aerosol data from Antarctica available for comparison have been obtained from central areas of the ice sheet. We must consider whether data collected from coastal sites are representative of a wider area. Long-range transport of primary aerosol from distant sources to Antarctica seems to take place in the middle troposphere generally by a process of eddy diffusion (Shaw 1979). Once over the continent slow vertical mixing processes transfer the aerosol to cloud levels where it is removed rapidly (in 1 to 2 d) by scavenging processes. Relatively long residence times ( 1 to 5 weeks) of aerosol in the Antarctic troposphere above the boundary layer, in combination with vigorous zonal mixing of air masses surrounding the continent, should yield a rather constant concentration of aerosols across the continent. This is supported by direct observation of a nearly constant total aerosol mixing ratio in the middle troposphere between the South Pole and the coast at

TABLE III. AIRBORNE CONCENTRATION OF TRACE ELEMENTS IN THE ANTARCTIC PENINSULA, SUMMER 1982-83 (all concentrations in $\mathrm{pg} \mathrm{m}^{-3}$ STP)

\begin{tabular}{cccccccccc} 
Run no. & $\mathrm{Cd}$ & $\mathrm{Cu}$ & $\mathrm{Pb}$ & $\mathrm{Zn}$ & $\mathrm{A} 1$ & $\mathrm{Na}$ & $\mathrm{Ca}$ & $\mathrm{K}$ \\
\hline 3 & $<1.2$ & $7.6 \pm 3.6$ & $<9$ & $<15.2$ & $880 \pm 130$ & $60000 \pm 6000$ & $3300 \pm 100$ & $3100 \pm 520$ \\
4 & $<0.9$ & $<4.3$ & $<7$ & $<11.5$ & $550 \pm 100$ & $36000 \pm 3600$ & $1500 \pm 80$ & $<640$ \\
5 & $<1.0$ & $<4.5$ & $<7$ & $14.3 \pm 7.6$ & $390 \pm 110$ & $18000 \pm 1800$ & $700 \pm 80$ & $<650$ \\
6 & $<0.7$ & $10.7 \pm 1.9$ & $<5$ & $9.8 \pm 5.4$ & $1110 \pm 70$ & $14000 \pm 1400$ & $900 \pm 60$ & $<460$ \\
12 & $<0.6$ & $7.6 \pm 1.7$ & $<13$ & $<7.2$ & $810 \pm 60$ & $38000 \pm 3800$ & $1800 \pm 50$ & $1600 \pm 240$ \\
14 & $<0.5$ & $3.6 \pm 1.5$ & $<4$ & $10.1 \pm 4.0$ & $590 \pm 55$ & $40000 \pm 4000$ & $1700 \pm 40$ & $1200 \pm 220$ \\
15 & $<1.2$ & $<5.8$ & $<9$ & $<15.2$ & $<208$ & $27000 \pm 2700$ & $900 \pm 100$ & $1600 \pm 520$ \\
16 & $<1.4$ & $<6.4$ & $<10$ & $<17.3$ & $260 \pm 150385000 \pm 38500$ & $14000 \pm 12015000 \pm 590$ \\
21 & $<0.6$ & $8.7 \pm 1.9$ & $<5$ & $10.5 \pm 5.1$ & $2360 \pm 70$ & $37000 \pm 3700$ & $1500 \pm 50$ & $1200 \pm 280$ \\
22 & $<1.5$ & $10.9 \pm 4.4$ & $<18$ & $<18.7$ & $660 \pm 160$ & $15000 \pm 1500$ & $600 \pm 130<1024$ \\
23 & $<1.2$ & $21.6 \pm 3.6$ & $<9$ & $19.5 \pm 9.5$ & $<208$ & $600 \pm 300$ & $<160$ & $<832$ \\
24 & $<2.7$ & $19.8 \pm 8.06$ & $<14$ & {$[53.1 \pm 21.2]$} & $620 \pm 300$ & $9300 \pm 930$ & $700 \pm 160<1328$ \\
26 & $<1.4$ & {$[41.1 \pm 4.1]$} & $<10$ & $19.3 \pm 10.8$ & $1100 \pm 160$ & $9500 \pm 950$ & $800 \pm 120<<1024$ \\
Mean* & $<1.1$ & $11.3 \pm 6.2$ & $<8.5$ & $13.9 \pm 4.5$ & $848 \pm 567$ & $53000 \pm 101000$ & $2366 \pm 3740$ & $3950 \pm 5459$
\end{tabular}

* Mean values calculated from concentrations not quoted as upper limits. 
TABLE IV. CONCENTRATION OF MAJOR ELEMENTS IN FALLING SNOW FROM THE ANTARCTIC PENINSULA, SUMMER 1982-83 (all concentrations in $\mathrm{ng} \mathrm{g}^{-1}$ )

\begin{tabular}{|c|r|c|c|c|}
\hline $\begin{array}{c}\text { Run } \\
\text { no. }\end{array}$ & $\mathrm{A} 1$ & $\mathrm{Na}$ & $\mathrm{Ca}$ & $\mathrm{K}$ \\
\hline 4 & 2.1 & 40.9 & 3.3 & - \\
5 & 1.5 & 59.0 & 2.5 & $<2.5$ \\
15 & 1.1 & 59.0 & 2.9 & $<2.5$ \\
16 & 0.3 & $419^{*}$ & 15.8 & 14.2 \\
20 & 1.1 & $358^{*}$ & 13.1 & 12.2 \\
22 & $<1.3$ & $<2.0$ & $<1.3$ & $<2.5$ \\
23 & $<1.5$ & $<3.1$ & 0.8 & \\
24 & $<1.5$ & $<2.4$ & $<0.3$ & $<2.5$ \\
$\sigma_{\text {tot }}$ & 0.9 & $2.0\left(30^{*}\right)$ & 0.2 & 1.5 \\
$\begin{array}{c}\text { Procedural } \\
\text { blank }\end{array}$ & 0.5 & 0.4 & $<0.3$ & 2.2 \\
\hline
\end{tabular}

McMurdo station (Hogan 1979). Hence the contribution of "background" aerosol in the Antarctic Peninsula should be similar to that found in the interior. Superimposed on this there may be more localized intrusions of aerosol from the neighbouring ocean and from exposed rock.

Al is often used as an indicator of crustal material. The average airborne concentration of $\mathrm{Al}$ from the two sites on the Antarctic Peninsula (Table V) is similar to that reported by Maenhaut and others (1979) and by Cunningham and Zoller (1981) for aerosol collections made during several summer seasons at the South Pole. Insoluble microparticles, which are mainly of crustal origin, have been examined by Thompson and Mosley-Thompson (1982) in firn cores collected from interior and coastal areas of Antarctica including two sites from the Antarctic Peninsula. A close similarity in the size distribution of microparticles at such widely separated sites suggests that they are derived from well-mixed and long-range sources. Hence local rock exposure in the Antarctic Peninsula does not seem to make a significant contribution to the input of crustal elements to large snowfields which have been studied in the area south of $70^{\circ} \mathrm{S}$.

Airborne concentrations of $\mathrm{Na}, \mathrm{K}$ and $\mathrm{Mg}$ at the South Pole are on the average three to ten times smaller than values reported here (Table V). Our data from both sites show high levels of correlation between these elements $(\mathrm{Na}: \mathrm{Ca}, \mathrm{r}=0.996 ; \mathrm{Na}: \mathrm{K}, \mathrm{r}=0.992)$ and the ratios between the concentrations of these elements conform closely with that of bulk sea-water. In the interior of Antarctica there is evidence for a crustal contribution to both $\mathrm{Ca}$ and $\mathrm{K}$ (Boutron 1982) which is masked in the Antarctic Peninsula by the proximity of the oceanic source. This source would however not be expected to make a significant contribution of $\mathrm{Cd}, \mathrm{Cu}, \mathrm{Pb}$ and $\mathrm{Zn}$ to the aerosol. Although an enrichment of $\mathrm{Pb}$ in the surface layers of the ocean and in sea spray has been reported, Boutron and Patterson (1983) estimate that this would lead to a concentration of only $0.025 \mathrm{pg} \mathrm{g}^{-1} \mathrm{~Pb}$ in snow in the Antarctic interior. Allowing for an input of marine aerosol that is ten times greater to the Antarctic Peninsula the associated contribution of $\mathrm{Pb}$ would be $0.25 \mathrm{pg} \mathrm{g}^{-1}$ (around $4 \%$ of the present-day concentration of $\mathrm{Pb}$ in Antarctic snow reported by Boutron and Patterson (1983) and Wolff and Peel (1985). Unless this oceanic source has been grossly underestimated we therefore believe that similar concentrations of these elements should exist in the Antarctic Peninsula and in the interior.

Although we are still able to present upper limit values only for the airborne concentrations of $\mathrm{Cd}$ and $\mathrm{Pb}$ (Table III) it is evident from Table $\mathrm{V}$ that the concentration or upper limits of $\mathrm{Cd}, \mathrm{Cu}, \mathrm{Pb}$ and $\mathrm{Zn}$ here are substantially lower than values reported from the South Pole by Maenhaut and others (1979) and by Cunningham and Zoller (1981). They are also smaller than values previously reported from the Antarctic Peninsula (Peel and Wolff 1982). In all these studies it was necessary to apply large and uncertain blank corrections to the data. Peel and Wolff reported that from 25 to $50 \%$ of the total mass of heavy metals collected was contributed by the blank. Although we have been able to reduce both the size and variability of the filter blank it still makes a significant contribution to the sample. It is possible that improvement in techniques may reduce these concentrations even further.

Boutron and Patterson (1983) cited evidence that recent measurements from American Samoa have shown lower airborne concentrations of $\mathrm{Pb}$ than any values previously reported from Antarctica. Antarctic air should contain lower

TABLE V. MEAN TRACE ELEMENT CONCENTRATIONS IN ANTARCTIC AIR (concentrations in $\mathrm{pg} \mathrm{\textrm {m } ^ { - 3 } \mathrm { STP } )}$

\begin{tabular}{|c|c|c|c|c|c|}
\hline Element & $\begin{array}{c}\text { Antarctic Peninsula } \\
\text { summer } 1982-83\end{array}$ & $\begin{array}{c}\text { Antarctic Peninsula } \\
\text { summer }\end{array}$ & $\begin{array}{c}\text { South Pole } \\
\text { summer } \\
1974-80\end{array}$ & $\begin{array}{c}\text { South Pole } \\
\text { summers } \\
1971-78\end{array}$ & $\begin{array}{c}\text { South Pole }^{4} \\
\text { winters } \\
1975-76\end{array}$ \\
\hline $\mathrm{Cd}$ & $<1.1$ & 3.4 & $<18$ & 49 & $<200$ \\
$\mathrm{Cu}$ & 11.3 & No data & 29 & 59 & 79 \\
$\mathrm{~Pb}$ & $<8.5$ & 184 & 27 or 76 & No data & No data \\
$\mathrm{Zn}$ & 13.9 & 80 & 33 & 35 & 77 \\
$\mathrm{Al}$ & 848 & No data & 820 & 830 & $<300$ \\
$\mathrm{Na}$ & 53000 & 94000 & 3300 & 5100 & 40000 \\
$\mathrm{Ca}$ & 2366 & No data & 490 & 550 & 1900 \\
$\mathrm{~K}$ & 3950 & 18200 & 680 & 610 & 1300 \\
\hline
\end{tabular}

1. This work.

2. From Peel and Wolff (1982). Averaging data from Spaatz Island and plateau site.

3. From Maenhaut and others (1979).

4. From Cunningham and Zoller (1981). 
concentrations of $\mathrm{Pb}$ since the continent is much more remote and is protected from the mid-latitude circulation by the polar convergence zone around $50^{\circ} \mathrm{S}$. Based on their data from recent snow they suggested an upper limit of 5 $\mathrm{pg} \mathrm{m}^{-3}$ for $\mathrm{Pb}$ in air over the Antarctic ice sheet. Our data tend to support this suggestion and we must conclude that previous literature values for heavy metal concentration in Antarctic air are probably strongly influenced by contamination.

\subsection{Crustal enrichment factors for heavy metals in the aerosol}

Crustal weathering is probably the principal natural source of heavy metals in the aerosol. In order to identify whether additional sources exist it is common practice to calculate enrichment factors $\left(E_{\text {crust }}\right)$ for each element relative to major reference elements (in this case A1) of exclusive crustal origin. Here these have been calculated using crustal abundances estimated by Taylor (1964) as follows:

$$
\mathrm{EF}_{\text {crust }}=\left[(\mathrm{X} / \mathrm{A} 1)_{\text {air }}\right] /\left[(\mathrm{X} / \mathrm{A} 1)_{\text {crust }}\right]
$$

where $\mathrm{X}$ is the concentration of the heavy metal element. Averaged $\mathrm{EF}_{\text {crust }}$ values from all our air sampling runs are given in Table VI in comparison with previous data from Antarctica. Our data can only be regarded as upper limits yet they still show that the $E_{\text {crust }}$ values for these elements may be very much lower than previously reported. Wolff and Peel (1985) report $E F_{\text {crust }}$ values for the heavy metals in recent summer snowfall from the Antarctic Peninsula which are somewhat lower than the values given here for the aerosol. Their values (with the exception of Cd) are similar to estimates of the ratio of present-day anthropogenic emission rates to natural airborne emission rates for these elements. Hence it seems likely that there may be no need to seek elaborate mechanisms for natural enrichment of these elements in the aerosol which have proved difficult to substantiate in the past $(\mathrm{Ng}$ and Patterson 1981).

\subsection{Short-term variations in the aerosol}

Within the limits of experimental error no significant differences in the heavy metal content of the aerosol were detected between individual sample collections at each site or between collections at the two sample sites (Table III). In contrast, large variations were observed for both Al (up to a factor of 9) and for the marine cations (up to a factor of 64). This suggests that crustal weathering and ocean spray are not major sources of heavy metals in the present-day aerosol.

The highest concentrations of Al were all recorded during runs undertaken under clean-air conditions where there was no precipitation (runs 6, 12, 21, and 26) and these values may be representative of the background aerosol. The marine cations showed much more variability, probably due to the proximity of the source. The aerosol burden in this case will be sensitive to local weather conditions over the sea and to the particular track taken by an air mass approaching the sampling site.

Three groups of sampling runs spanned periods of continuous snowfall (3-4-5, 14-15-16 and 22-23-24). A systematic decrease in the concentration of both $\mathrm{Al}$ and the marine cations was observed during the most stable event (3-5) and during the first two days of events 14-16 and 22-24. In these latter cases a further increase in concentration occurred on the third day, possibly associated with a change in wind direction and a new weather system. These decreases in the aerosol concentration probably reflect a progressive scavenging of the aerosol by snowfall. The effect has been noted by several authors for precipitation events in less remote regions (Nürnberg and others 1982).

\subsection{Relationship between aerosol and snowfall composition} Junge (1977) has considered that four major processes are responsible for removing aerosol from the atmosphere: nucleation of cloud droplets, scavenging of unactivated aerosols within cloud, scavenging of aerosol below cloud by precipitation, and dry deposition. $\mathrm{He}$ concluded that nucleation was the dominant removal mechanism for the clean-air conditions which occur over the polar ice sheets. Shaw (1980) has examined the size distribution and vertical variation of the total aerosol over the Antarctic ice sheet and calculated that $90 \%$ of the total aerosol could be removed by nucleation. For this process Junge showed that the concentration of a given element in air $\left(\mathrm{C}_{\text {air }}\right)$ should be proportional to its concentration in snowfall $\left(\mathrm{C}_{\text {snow }}\right)$ according to the relationship:

$\left[\mathrm{C}_{\mathrm{air}}\left(\mathrm{pg} \mathrm{m} \mathrm{m}^{-3}\right)\right] /\left[\mathrm{C}_{\text {snow }}\left(\mathrm{pg} \mathrm{g}^{-1}\right)\right]=\mathrm{L} / € \eta=\Phi\left(\mathrm{g} \mathrm{m}^{-3}\right)$

where $\mathrm{L}$ is the liquid water content of the cloud, $\epsilon$ is the mass fraction of aerosols used for condensation (expected to lie in the range $0.5<\epsilon<1.0)$ and $\eta$ is a factor $(>1)$ to allow for evaporation of snowflakes below the cloud base. $\epsilon$, which is effectively a nucleation efficiency, may be sensitive to the size, shape and chemical properties of the aerosol. $\eta$ is dependent on both the height of the cloud base and the relative humidity of the air below the cloud.

It is important to determine how far $\Phi$ can be considered constant for a given trace element over a range of weather conditions and across a wide geographical area. If fractionation is a significant factor then different values of $\$$ may be expected for different types of element. In Table VII we give values of $\Phi$ for $\mathrm{Al}, \mathrm{Na}, \mathrm{Ca}$ and $\mathrm{K}$ from individual runs in which air and snowfall were sampled simultaneously. In all cases, during snowfall events the

TABLE VI. MEAN CRUSTAL ENRICHMENT FACTORS FOR HEAVY METALS IN ANTARCTIC AIR

\begin{tabular}{|c|c|c|c|c|}
\hline Element & $\begin{array}{c}\text { Antarctic Peninsula } \\
\text { summer } 1982-83\end{array}$ & $\begin{array}{c}\text { South Pole } \\
\text { summer 1974-75 }\end{array}$ & $\begin{array}{c}\text { South Pole } \\
\text { summers 1975-78 }\end{array}$ & $\begin{array}{c}\text { Antarctic Peninsula } \\
\text { summer snow 1979-80 }\end{array}$ \\
$\mathrm{Cd}$ & $<533$ & $<9000$ & $<24000$ & $182 \pm 94$ \\
$\mathrm{Cu}$ & $20 \pm 11$ & $25-100$ & $20-140$ & $4.5 \pm 2.1$ \\
$\mathrm{~Pb}$ & $19 \pm 6$ & $100-1000$ & No data & $68 \pm 35$ \\
$\mathrm{Zn}$ & $19 \pm$ & $30-90$ & $20-110$ & $6.3 \pm 3.2$ \\
\hline
\end{tabular}

1. This work.

2. From Maenhaut and others (1979).

3. From Cunningham and Zoller (1981).

4. From Wolff and Peel (1985). 
TABLE VII. VALUES OF $\$$ (CONCENTRATIONS IN AIR $\mathrm{pg} \mathrm{m}^{-3}$ STP/CONCENTRATIONS IN SNOW $\mathrm{pg}$ $\mathrm{g}^{-1}$ ) FOR MAJOR ELEMENTS FROM SIMULTANEOUS SAMPLING IN THE ANTARCTIC PENINSULA. COMPARISON WITH AVERAGED VALUES OBTAINED FROM SEPARATE SAMPLING IN THE ANTARCTIC PENINSULA ${ }^{1}$ AND AT THE SOUTH POLE ${ }^{2}$

\begin{tabular}{rllllll}
\hline $\begin{array}{r}\text { Run } \\
\text { no. }\end{array}$ & Al & Na & Ca & K & Mg \\
\hline
\end{tabular}

\begin{tabular}{lccccc}
4 & 0.26 & 0.88 & 0.45 & - & - \\
5 & 0.26 & 0.30 & 0.28 & - & - \\
15 & - & 0.46 & 0.58 & - & - \\
16 & 0.99 & 0.92 & 0.88 & 1.06 & - \\
22 & 0.52 & - & 0.34 & - & - \\
23 & - & 0.55 & - & - & - \\
$\begin{array}{l}\text { Mean Antarctic } \\
\text { Peninsula }\end{array}$ & 0.51 & 0.62 & 0.51 & 1.06 & - \\
$1982-83$ & & & & & \\
$\begin{array}{l}\text { Mean Antarctic } \\
\text { Peninsula } \\
1979-80^{1}\end{array}$ & - & 0.33 & - & 0.94 & 0.35 \\
$\begin{array}{l}\text { South Pole } \\
1971-78^{2}\end{array}$ & 0.67 & 2.05 & 1.57 & 1.07 & 1.96 \\
\hline
\end{tabular}

1 From Peel and Wolff (1982).

2 Air concentrations obtained by averaging summer and winter values in the period 1971 to 1978 from Cunningham and Zoller (1981). Snow concentrations calculated as the average for 1970 to 1977 from Boutron (1982).

stratus cloudbase lay within $100 \mathrm{~m}$ of the surface and the relative humidity near the surface was in the range from 86 to $100 \%$ so that the possibilities for below-cloud scavenging and evaporation of snowflakes were very limited. The averaged $\Phi$ values for $\mathrm{Al}, \mathrm{Na}$ and $\mathrm{Ca}$ are similar, indicating that there is no important fractionation between crustal and marine-derived aerosol. A value for $\mathrm{L}$ (Equation (1)) in the range from 0.21 to $0.62 \mathrm{~g} \mathrm{~m}^{-3}$ is implied which is reasonable for stratiform clouds at the temperatures $(-1$ to $-16^{\circ} \mathrm{C}$ ) encountered during sampling.

The only values of $\Phi$ available for comparison from simultaneously sampled air and snow from Antarctica were reported by Peel and Wolff (1982) from three different sites (marked by triangles in Fig.1) in the Antarctic Peninsula. Their average value for the marine ions $\mathrm{Na}, \mathrm{Mg}$ and $\mathrm{K}$ was $0.54 \pm 0.37$, which is in good agreement with the value of $0.57 \pm 0.29$ obtained here for $\mathrm{Na}$ and $\mathrm{Ca}$.

Although simultaneous sampling has not been reporte at the South Pole, extensive aerosol data have been obtained over four summer and two winter seasons during the period 1970 to 1978. Cunningham and Zoller (1981) presented averaged data for summer and winter concentrations for a range of trace elements over this period. These data can be compared with values reported by Boutron (1982) for South Pole firn which cover the same period. The resultant values of $\Phi$ for $A 1$ and the marine ions are reported in Table VI. Values of $\Phi$ obtained for the marine ions at the South Pole are slightly, yet consistently, larger than values obtained from simultaneous air and snow sampling in the Antarctic Peninsula. Pourchet and others (1983) have estimated that $40 \%$ of the radionucleide content of South Pole snow may result from dry deposition. If applicable to the marine ions, this would lead to a proportionate increase in the values of $\Phi$ if air and snowfall were sampled simultaneously at the South Pole. For a remote site in south-central Greenland, Davidson and others (1981) have reported a substantially larger value for $\mathrm{Mg}(\Phi=5.6)$ for samples collected simultaneously. A possible explanation is that in the Antarctic Peninsula the marine aerosol is much closer to its source and will have a larger size distribution. More efficient removal by nucleation (i.e. $\epsilon$ closer to 1 in Equation (1)) might therefore be expected. The two data sets yield similar values of $\Phi$ for A1. This may indicate that dry deposition does not make a significant input to South Polar snow, in contrast to the findings of Pourchet and others (1983) for the radionucleides. Direct analysis of fresh and aged snowfall at the South Pole is needed to resolve this question.

We do not yet have data for the heavy metal content of the simultaneously sampled snowfall. However, Wolff and Peel (1985) have analyzed $\mathrm{Cd}, \mathrm{Cu}, \mathrm{Pb}$ and $\mathrm{Zn}$ in fresh summer snowfall collected during February 1980 from sites on the southern Palmer Land plateau. Similar concentrations for each element were recorded over the $100 \mathrm{~km}$ sampling line. Five samples drawn from a section of firn representing approximately 6 months snowfall from Spaatz Island, which lies close to the Beethoven Peninsula occupied here, gave concentrations of $\mathrm{Pb}$ within the range of values observed on the plateau. Hence it appears that the spatial and temporal variations of these elements may not be great. We have therefore estimated provisional values of $\Phi$ for these elements by comparing average airborne concentrations observed here with average snowfall data from Wolff and Peel. The results are summarised in Table VIII along with $\Phi$ values compiled by Boutron (in press) for the South Pole based on non-simultaneous collections during the period 1970 to 1978 .

TABLE VIII. VALUES OF $\Phi$ (CONCENTRATION IN AIR, $\mathrm{pg} \mathrm{m}^{-3} /$ CONCENTRATION IN SNOW, $\mathrm{pg} \mathrm{g}^{-1}$ ) FOR HEAVY METALS IN THE ANTARCTIC PENINSULA AND AT THE SOUTH POLE

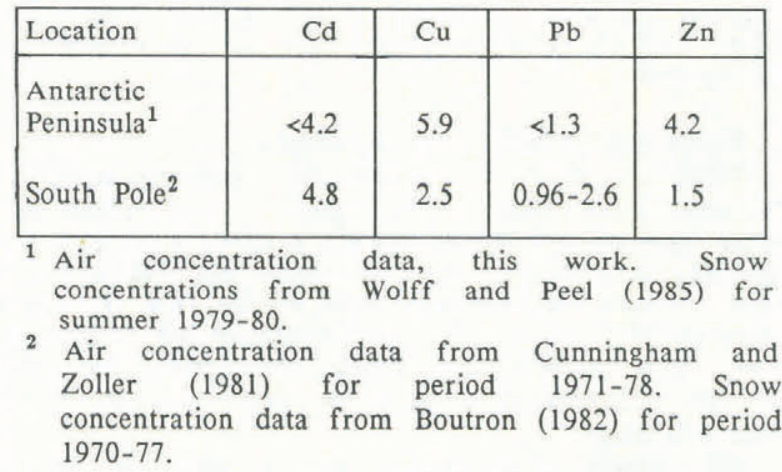

Although our values are necessarily tentative they still show good agreement with values predicted theoretically by Junge (1977). Agreement with the South Pole data set is probably fortuitous since the snowfall concentration data from this site have subsequently been demonstrated by Boutron and Patterson (1983) to be erroneous and the atmospheric concentrations are also very much larger than concentrations reported here. For the Antarctic Peninsula the values of $\Phi$ for the heavy metals are higher than those for the major crustal and marine elements, but this too may reflect a residual contamination problem in our air sampling data.

$\mathrm{Ng}$ and Patterson (1981) have given evidence from several remote areas that present-day $\mathrm{Pb} / \mathrm{Si}$ dust ratios are, on the average, 10 -fold smaller in the air than in rain or snow collected at the same time. They argue that industrially produced $\mathrm{Pb}$ is associated with particles much smaller than natural dust particles and can consequently be scavenged by diffusion much more efficiently onto cloud droplets or snowflakes. If this is a global phenomenon, as indicated by the authors, then it would have important implications for interpreting long time series of $\mathrm{Pb}$ concentrations in Antarctic ice cores in terms of atmospheric trends. However, the only data cited in support from Antarctica must now be considered suspect. We have used Al as a crustal index and this would be expected to behave 
in exactly the same way as $\mathrm{Si}$. If the enrichment mechanism were operating we would expect to see values of $\Phi$ for $\mathrm{Pb}$ some 10 -fold smaller than those for Al. This is not substantiated by the data available from the Antarctic Peninsula. The strongest support for $\mathrm{Ng}$ and Patterson's proposition came from sites in the northern hemisphere. Anthropogenic aerosol arriving in Antarctica will have travelled much further in the atmosphere and is unlikely to have retained its original identity. More precise data from Antarctica are now required to help resolve this important question.

\section{CONCLUSIONS}

Improvements in contamination control have made it possible, for the first time in Antarctica, to compare aerosol and snowfall composition over individual precipitation events. The rate of incorporation of major crustal and marine elements into snowfall seems to accord with the predictions of a simple model due to Junge which accounts only for in-cloud scavenging. A crude comparison of average heavy-metal concentrations in air and snowfall for different summer periods gives no evidence for any fractionation between crustal, marine and heavy-metal components of the aerosol during precipitation.

Airborne concentrations of heavy metals reported here are lower than any previously reported in Antarctica. As a result, although the filter blank has been substantially reduced in this work, observed concentrations still lie close to the detection limit. With little prospect of further reducing the blank, larger volumes of air must be sampled in order to increase the accuracy of the data. This could in part be achieved by increasing the filter pore size to 0.8 $\mu \mathrm{m}$ to reduce any loss of time resolution. Analysis of simultaneously collected snowfall must be extended to the heavy metals to improve on the crude comparisons achieved so far. In addition, sampling of fresh and aged surface snow in areas of low accumulation should make direct measurement of dry deposition rates possible. The interpretation of trace-element profiles in ice cores in terms of atmospheric changes will have a firmer basis when the contribution of both wet and dry deposition has been quantified.

\section{ACKNOWLEDGEMENTS}

The authors would like to acknowledge, with thanks, the support received from all personnel at Rothera station during $1982-83$ and in particular the able assistance of Simon J R Fraser in the field.

\section{REFERENCES}

Boutron C F 1982 Atmospheric trace metals in the snow layers deposited at the South Pole from 1928 to 1977. Atmospheric Environment 16 (10): 2451-2459

Boutron $C$ F In press Atmospheric toxic metals and metalloids in the snow and ice layers deposited in Greenland and Antarctica from prehistoric times to present. In Davidson C I, Nriagu J O (eds) Toxic metals in the air. New York, John Wiley and Sons

Boutron C F, Lorius C 1979 Trace metals in Antarctic snows since 1914. Nature 277 (5697): 551-554

Boutron C F, Patterson C C 1983 The occurrence of lead in Antarctic recent snow, firn deposited over the last two centuries and prehistoric ice. Geochimica et Cosmochimica Acta 47: 1355-1368

Cunningham W C, Zoller W H 1981 The chemical composition of remote area aerosols. Journal of Aerosol Science 12(4): 367-384

Davidson C I, Chu L, Grimm T C, Nasta M A, Qamoos M P 1981 Wet and dry deposition of trace elements onto the Greenland ice sheet. Atmospheric Environment 15 (8): 1429-1437

Derrick M, Moyers J 1981 Precise and sensitive water soluble ion extraction method for aerosol samples collected on polytetrafluorethylene filters. Analytical Letters 14 (A19): 1637-1652

Hogan A W 1979 Meteorological transport of particulate material to the south polar plateau. Journal of Applied Meteorology 18 (6): 741-749
Junge C E 1977 Processes responsible for the trace content in precipitation. International Association of Hydrological Sciences Publication 118 (General Assembly of Grenoble 1975 - Isotopes and Impurities in Snow and Ice): 63-77

Maenhaut W, Zoller W H, Duce R A, Hoffman G L 1979 Concentration and size distribution of particulate trace elements in the south polar atmosphere. Journal of Geophysical Research 84 (C5): 2421-2431

Megaw W J, Wiffen R D 1963 The efficiency of membrane filters. International Journal of Air and Water Pollution 7: $501-509$

$\mathrm{Ng} \mathrm{A}$, Patterson C C 1981 Natural concentration of lead in ancient Arctic and Antarctic ice. Geochimica et Cosmochimica Acta 45(11): 2109-2121

Nguyen V D, Valenta P, Nürnberg H W 1979 The determination of toxic trace metals in rainwater and snow by differential pulse stripping voltammetry. Science of the Total Environment 12: 151-167

Nürnberg H W, Valenta P, Nguyen V D 1982 Wet deposition of toxic metals from the atmosphere in the Federal Republic of Germany. In Georgii H-W, Pankreth $\mathrm{J}$ (eds) Deposition of atmospheric pollutants. Dordrecht, D. Reidel: 143-157

Peel D A, Wolff E W 1982 Recent variations in heavy metal concentrations in firn and air from the Antarctic Peninsula. Annals of Glaciology 3: 255-259

Pourchet M, Pinglot F, Lorius C 1983 Some meteorological applications of radioactive fallout measurements in Antarctic snows. Journal of Geophysical Research 88 (C10): 6013-6020

Rahn K A, McCaffrey R J 1979 Compositional differences between Arctic aerosol and snow. Nature 280 (5722): 479-480

Rohbok E 1982 Atmospheric removal of airborne metals by wet and dry deposition. In Georgii H-W, Pankreth J (eds) Deposition of atmospheric pollutants. Dordrecht, D. Reidel: $159-171$

Shaw G E 1979 Considerations on the origin and properties of the Antarctic aerosol. Reviews of Geophysics and Space Physics 17(8): 1983-1998

Shaw G E 1980 Optical, chemical and physical properties of aerosols over the Antarctic ice sheet. Atmospheric Environment 14(8): 911-921

Taylor S R 1964 Abundance of chemical elements in the continental crust: a new table. Geochimica et Cosmochimica Acta 28: 1273-1285

Thompson L G, Mosley-Thompson E 1982 Spatial distribution of microparticles within Antarctic snow-fall. Annals of Glaciology 3: 300-306

Wolff E W, Peel D A 1985 Closer to a true value for heavy metal concentrations in recent Antarctic snow by improved contamination control. Annals of Glaciology 7: 61-69 